\title{
La Vicepresidencia y las coaliciones políticas: el caso de Argentina
}

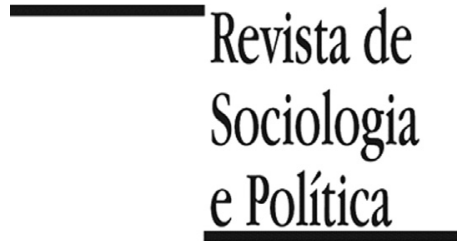

DOI $10.1590 / 1678-987317266502$

\begin{abstract}
Mario Daniel Serrafero ii
RESUMEN Introdución: El artículo se propone estudiar la Vicepresidencia y su papel en la conformación de las coaliciones políticas. La Vicepresidencia es una institución poco estudiada en América Latina. En los diferentes países presentan funciones que pueden ser distintas, pero hay una en común: el reemplazo del Presidente en caso de ausencia temporal o definitiva. El trabajo analiza el caso argentino y toma el gobierno de la Alianza (1999-2001) y el de Cristina Kirchner y su Concertación Plural (2007-2011). En ambos casos el Vicepresidente fue de un partido distinto al del Presidente y que conformaba la coalición o el acuerdo político. Métodos: El estudio considera factores normativos y políticos. El normativo se refiere a las facultades constitucionales de la Vicepresidencia. Los políticos son: el modo de designación del Vice; el tipo de relación que se establece entre el Presidente y el Vicepresidente; el papel que le asigna el Presidente a su Vice; el modo en que el Vicepresidente desempeña su papel; y el peso de las fuerzas políticas que los mismos representan. Resultados: Los resultados del estudio muestran la importancia de la relación entre el Presidente y el Vicepresidente para el mantenimiento de las coaliciones poco institucionalizadas y donde las facultades de los Vicepresidentes son ambiguas o reducidas. Discusión: El resultado del artículo agrega perspectivas a la incipiente discusión sobre las funciones y la utilidad de la Vicepresidencia especialmente cuando esta institución sella acuerdos o coaliciones de gobierno. El estudio aporta una clasificación sobre los tipos de Presidente y de Vicepresidente, cuya combinación puede significar situaciones de cooperación o de conflicto que pueden influir en el éxito o el fracaso de la coalición de gobierno.
\end{abstract}

PALABRAS-CLAVE: Vicepresidencia; coaliciones políticas; presidencia; presidencialismo; América Latina.

Recibido en el 1 de noviembre de 2016. Aprobado en el 25 de Febrero de 2017.

\section{Introducción ${ }^{1}$}

\footnotetext{
${ }^{1}$ Agradecemos las sugerencias y comentarios de los dictaminadores anónimos de la Revista de Sociologia e Política.
}

L a Vicepresidencia en América Latina es una institución poco estudiada. En los diferentes países presenta funciones y facultades que pueden ser distintas, pero hay una común en todos: reemplazar al Presidente en caso de ausencia temporal o definitiva, en el marco de las condiciones establecidas en cada Constitución. Esto convierte a la Vicepresidencia en un lugar que es relevante por la mera expectativa de alcanzar el poder, en caso de una eventualidad. Cuando un partido compite por la Presidencia, el Vicepresidente puede provenir de un sector del mismo partido con el fin de afianzar la cohesión interna y maximizar el rendimiento electoral. Pero cuando es una coalición la que lucha por la primera magistratura la Vicepresidencia puede ser un lugar esencial para la conformación de la fuerza política. En síntesis, la Vicepresidencia es un sitio especial para sellar coaliciones políticas en los sistemas presidenciales. ¿Cuál es el papel del Vice en las coaliciones? ¿Qué factores influyen en el papel que desempeña? ¿Cómo influye y que aporta la Vicepresidencia respecto del mantenimiento o la desintegración de una coalición?

Aquí se considera que algunos factores relevantes son de tipo normativo y otros de tipo político. Respecto de los normativos cabe considerar, especialmente, las facultades, atribuciones y competencias que el diseño constitucional le asigna al Vicepresidente. Entre los factores políticos cabe consignar el modo de designación del Vice, el tipo de relación que se establece entre Presidente y Vicepresidente, el papel que le asigna el Presidente a su Vice, el modo en que el Vicepresidente desempeña su papel y el peso de las fuerzas políticas que los mismos representan. El trabajo pone foco en la Argentina con dos experiencias distintas que tuvieron en común la ocupación de la Vicepresidencia por un 
político de un partido distinto al del Presidente: el caso de la Alianza, la coalición que gobernó la Argentina entre 1999 y 2001 y la experiencia de la primera presidencia de Cristina Kirchner (2007 - 2011) que, si bien no fue una coalición, se presentó como un acuerdo entre el Frente para la Victoria y un sector del radicalismo.

Cuando los arreglos institucionales que favorecen la consolidación de las coaliciones están ausentes, son muy débiles o precarios, y en la coalición - o el acuerdo - la Vicepresidencia ha ocupado un lugar central en su constitución, la relación y los intereses de los componentes de la fórmula presidencial cobran un papel que puede ser fundamental en el mantenimiento de la fuerza política. Asimismo, cuando las funciones constitucionales del Vicepresidente son reducidas en el terreno ejecutivo (más allá de su papel de reemplazo del Presidente cuando se cumplen las condiciones que señala la norma constitucional), la actitud y el comportamiento del Presidente respecto del Vice y de éste respecto del Presidente son factores relevantes para ampliar o reducir el papel de la Vicepresidencia en el sistema político y, específicamente, en el marco de una coalición o acuerdo político. En el trabajo se sostiene que, tanto el papel asignado por el Presidente al Vice, como el mismo comportamiento del Vice y la relación establecida entre ambos fueron causas relevantes que motivaron la disolución progresiva de la coalición en el gobierno de la Alianza (1999 - 2001) presidido por Fernando de la Rúa y del acuerdo político o "Concertación Plural” en el gobierno kirchnerista presidido por Cristina Kirchner(2007 - 2011).

El estudio - que no es definitivo, sino un avance sobre el tema Vicepresidencia y coaliciones - comienza con una breve y acotada introducción teórica de la Vicepresidencia en el sistema presidencial y en referencia a las coaliciones de gobierno. Luego se aborda la institución Vicepresidencial en los contextos electorales y, principalmente, en el de gobierno. Respecto del contexto de gobierno se profundiza lo desarrollado en estudios anteriores (Serrafero 1999) respecto de la relación entre Presidente y Vice. A continuación se tratan los casos referidos y por último se reflexiona sobre el papel de la Vicepresidencia en los presidencialismos de coalición, teniendo en cuenta la propuesta del trabajo y los casos analizados. Otros enfoques y nuevos casos a tratar abrirán el panorama de conocimiento en un tema poco estudiado hasta el presente. Los atributos esenciales de los tipos de Vicepresidente y de Presidente son discutidos en el apéndice 1.

\section{Presidencialismo, Vicepresidencia y coaliciones}

En la mayoría de los países latinoamericanos existe la institución de la Vicepresidencia. En los Estados Unidos la Vicepresidencia ha sido materia de análisis y existen trabajos de ineludible cita (Goldstein 1982; 2008; Light 1984). La experiencia norteamericana, su evolución y la producción teórica pueden aportar no pocas lecciones para el caso latinoamericano. Respecto de la Vicepresidencia latinoamericana existen no pocos misterios y paradojas, como así también un incipiente debate, en algunos países, sobre sus características, desempeño y verdadera utilidad. Lo cierto es que han sido significativos los problemas que rodearon a la Vicepresidencia latinoamericana en la tercera ola de la democratización, y aún antes. En Argentina, Bolivia, Colombia, Ecuador, Paraguay, para mencionar algunos casos, encontramos conflictos significativos cuando no de extrema gravedad en la relación entre el Presidente y el Vicepresidente. Pero también ha cumplido funciones importantes en algunos países en momentos críticos, por ejemplo, en Brasil. El interés que ha suscitado la institución ha merecido nuevos estudios que focalizan, concretamente, la Vicepresidencia en América Latina (Shribman 2009; Marsteintredet 2013; Mieres y Pampín 2015). 
Según se ha sostenido en estudios anteriores (Serrafero 1999; 2013), gran parte del problema reside en el diseño original de la institución. Para el Presidente, el Vice es una suerte de sombra que le pisa los talones y que apuesta, consciente o inconscientemente, a su desgracia. Para el Vicepresidente su lugar es el de la máxima paradoja: de no ser nada puede convertirse en todo, si esa desgracia finalmente le ocurre al mandatario. Por cierto esto no es siempre ni necesariamente así, pero el diseño institucional del presidencialismo en general y de la Vicepresidencia en particular puede coadyuvar a que estas fantasías tengan intento de concreción. El Vicepresidente mientras está el Presidente gobernando prácticamente no ocupa ningún papel relevante. En algunos países, como en la Argentina, tiene a su cargo la Presidencia del Senado, pero aun así aparece desdibujado de la escena política y gubernamental. En otros países desempeñan tareas en el campo ejecutivo y, específicamente, las que le delegue el Presidente. La variación de las facultades y funciones es importante, aunque su principal sentido o esencia es ser pieza de reemplazo del Presidente frente a determinadas circunstancias que pueden ocurrir en el horizonte político y que se encuentran determinadas en las constituciones.

En una investigación sobre la Vicepresidencia (Serrafero 1999), señalaba que respecto de esta institución existía una perspectiva desde la "visión clásica" proveniente, principalmente, desde el derecho constitucional. Se veía la Vicepresidencia como una institución que, frente a determinados hechos consignado por la normativa, sería un reemplazo legal y automático de la presidencia. Como señalé en mi investigación, esta "visión clásica" no era correcta y, por el contrario, afirmaba que: a) la asunción del Vicepresidente - en forma definitiva - implica una previa crisis institucional. En otras palabras, la Vicepresidencia es una institución o un dispositivo de crisis. b) La Vicepresidencia no garantiza una sucesión legal - automática. c) Hace falta construir una legitimidad de reemplazo en cabeza del Vicepresidente que asume para que puede superarse la crisis institucional. $\mathrm{Y}$ en la construcción de la legitimidad de reemplazo intervienen factores políticos de distintos tipo vinculados al origen institucional de la crisis, la situación político - social previa, el momento del mandato en que se produce la crisis, el estado de legitimidad del Presidente y del Vice, el grado de identificación con el Presidente, la experiencia y el estilo político del Vicepresidente, etc.

Por otra parte, en esa investigación (Serrafero 1999) se afirmaba que la Vicepresidencia podría cumplir o desempeñar otras funciones que las designadas en las Constituciones. Una de ella era la de obrar como pieza que favorecería la conformación de coaliciones en los presidencialismos. El estudio de las coaliciones fue un campo cultivado en relación con los sistemas parlamentarios y tratado por destacados investigadores (Downs 1973; Riker 1962; Strøm, Budge \& Laver 1994; Laver \& Shepsle 1990; Laver \& Budge 1993).

En las discusiones sobre el presidencialismo, en los ochenta, se suponía que se trataba de un fenómeno propio del parlamentarismo y ajeno al presidencialismo. Como tantas cosas, faltaba poner foco en el tema (Deheza 1998) y estudiarlo más profundamente. Fue así que comenzaron a aparecer estudios que pusieron luz a la cuestión. Y, por otra parte, se fueron sucediendo experiencias de coaliciones de gobierno en sistemas presidenciales. Los casos de Chile y de Brasil son claros ejemplos. La conformación de las coaliciones en el presidencialismo obedeció a distintas necesidades como la imposibilidad de conformar mayorías para gobernar, la necesidad de apoyo parlamentario para legislar y para tener soporte de gobernabilidad (Nolte 1999). Distintos trabajos sostuvieron aspectos relevantes sobre las coaliciones en los presidencialismos y su comparación con los otros regímenes. Cuestión estrechamente vinculada con las coaliciones fue la integración de gabinetes multipartidarios pues estos fueron generalmente reflejo de coaliciones en el marco de los presidencialismos 
(Inácio 2013; Dávila 2013). Pero prácticamente no apareció la figura de la Vicepresidencia en los análisis sobre el presidencialismo de coalición o las coaliciones en los presidencialismos (Altman 2000; Cheibub, Przerorski \& Saiegh 2003; Chasquetti 2006; Neto \& Samuels 2010; Reniu \& Albala 2012).

Como se mencionó y se verá más adelante, la fórmula presidencial mixta suele reflejar una situación de coalición de gobierno o bien un acuerdo con otra fuerza política distinta a la del Presidente. Existen distintos tipos y grados de formalización de las coaliciones. Para definir si nos encontramos ante una coalición institucionalizada el acuerdo y el compromiso entre los actores deben exteriorizarse y materializarse, al menos, en la integración del gabinete y en la actividad legislativa en el Congreso y, obviamente, en el compromiso con las políticas llevadas a cabo, que implica el mantenimiento de la coalición o los acuerdos a pesar de los problemas de gobernabilidad que pudieren existir e incluso frente a eventuales fracasos electorales. Si ello no ocurre, probablemente nos encontraríamos con una coalición que no tiene un diseño que la haga viable y que no funcionaría como tal en el ejercicio del gobierno. En la Argentina, como en el Brasil, la Vicepresidencia ha sellado coaliciones, con distinta suerte. Pero en el caso de Brasil han existido otros arreglos que responden a un diseño de coalición institucionalizada, a diferencia de la Argentina. En este sentido, así como la Vicepresidencia puede ser útil para rubricar una coalición, también podría ser perjudicial para su mantenimiento si entre Presidente y Vice existe una relación conflictiva en el contexto de gobierno y, sobre todo, si el diseño institucional de la coalición es pobre y se basa, principalmente sino exclusivamente, en la fórmula de Presidente y Vice.

Países que han tenido experiencias exitosas en materia de coaliciones de gobierno fueron y son - entre otros - Chile y Brasil. En Chile no existe la figura de la Vicepresidencia, pero sí en Brasil. Tanto en Chile como en Brasil las coaliciones gobernantes han conformado el diseño institucional de sus alianzas en el modo de integración de los gabinetes presidenciales y en una serie de reglas de funcionamiento. Pero en el Brasil, además, se ha utilizado la fórmula presidencial. En este país, el Presidente ha sido del principal partido de la coalición y la Vicepresidencia ha ubicado a un político de otro partido de la fuerza. Con Fernando Henrique Cardoso en la presidencia, lo acompañó Marco Maciel del Partido del Frente Liberal. A Lula, del PT, la acompañó como Vicepresidente José Alencar, del Partido Liberal. A Dilma Rousseff, del PT lo acompañó Michel Temer, del Partido del Movimiento Democrático Brasileño. Lo interesante de todos estos casos es que se trataron de Presidentes que fueron reelectos y que estuvieron acompañados por los mismos Vices en su segundo turno. El hecho per se muestra que entre Presidente y Vice se estableció un vínculo que fue relativamente positivo y armonioso para la continuidad de la fórmula bajo la cual descansaba la coalición. Claro está que la coalición puede deteriorarse si el Presidente ingresa en un proceso acelerado de pérdida de legitimidad, como ocurrió justamente con Rousseff. En este tipo de situaciones es esperable que el Vicepresidente se distancie del mandatario y frente a tal actitud el Presidente suele tratar al Vice como un conspirador. La crisis que envolvió a la destituida Presidenta Rousseff y la sucesión de Temer dan cuenta de estos movimientos de acercamiento y distanciamiento entre Presidente y Vice.

Argentina constituye un caso distinto, donde la relación entre Presidente y Vice, desde la redemocratización, no fue por cierto armoniosa. Y los Presidentes que resultaron reelectos tuvieron distintos Vicepresidentes en sus repeticiones, justamente por las desarmonías y hasta conflictos con sus compañeros de ruta. La literatura - como se dijo - prácticamente soslayó el hecho de que la fórmula presidencial suele reflejar y hasta sellar la conformación de coaliciones. ¿Se trata de una mera cuestión ornamental o resultan relevantes la 
existencia y la ocupación de la Vicepresidencia por un partido distinto del Presidente para la conformación de las coaliciones?

Básicamente, un presidencialismo que cuente con la figura del Vicepresidente y despliegue un formato de coalición, muy probablemente utilizará la Vicepresidencia en el esquema coalicional. En este sentido, cabe especular que: $a$ ) para la conformación de la coalición en un sistema presidencialista, la Vicepresidencia suele ser ocupada por un político de un partido coaligado (aquí resultan significativas las variables relativas a la designación del Vice, en el marco del contexto electoral); b) para el mantenimiento de la coalición, la relación entre Presidencia y Vicepresidencia puede convertirse en una cuestión crucial (aquí resultan significativas las variables relativas al contexto de gobierno y que se vinculan con la relación Presidente - Vicepresidente); c) en caso de producirse un "accidente institucional" asumiría el Vicepresidente y tal hecho es probable que modifique el funcionamiento mismo de la coalición o que directamente deje de existir.

Por otra parte, es probable que el tipo de relación entre Presidente y Vice afectará significativamente a las coaliciones de gobierno, dependiendo de su grado de institucionalización. Las coaliciones de gobierno que están constituidas a partir de la fórmula entre Presidente y Vice, podrán tener distintos destinos. Si se trata de coaliciones institucionalizadas, la buena o mala relación entre Presidente y Vice no tendrá efectos significativos. La coalición tiene una estructura institucional que puede soportar las desavenencias graves entre los miembros del binomio y el papel del Vice sería menos influyente

En cambio, si se trata de coaliciones poco institucionalizadas el tipo de relación que se establece entre ambos puede tener importantes consecuencias. Casi todo el peso del mantenimiento de la coalición reposa en la buena relación entre Presidente y Vice, lo que la hace mucho más precaria y vulnerable en caso de conflictos graves entre los miembros del binomio pues la coalición no está consolidada y el papel del Vice - sobre todo si es jefe o líder de su partido puede tener mayor capacidad de daño en la coalición gobernante.

La relación entre Presidente y Vice mientras coexisten en el gobierno dependerá del tipo del Presidente y Vicepresidente en cuestión, estableciéndose diferentes ambientes que van desde la confianza mutua hasta el conflicto manifiesto. En otras palabras, la buena o mala relación dependerá del tipo de Presidente y de Vicepresidente que constituyen la fórmula que sella la coalición. Se trata de una relación dinámica y por lo tanto, cambiante.

Así como la Vicepresidencia puede ser útil para rubricar una coalición, también podría ser perjudicial para su mantenimiento si entre Presidente y Vice existe una relación de desconfianza, tensión o conflicto recurrente en el contexto de gobierno y, sobre todo, si el diseño institucional de la coalición es pobre y se basa, principalmente sino exclusivamente, en la fórmula de Presidente y Vice, (y éste es jefe o líder de su partido, importante en el esquema de coalición). Obvio es decir que también tendrá importancia el tipo de Presidente pues se trata de una interacción entre dos personas que se va modificando de acuerdo a los comportamientos de ambos. Por último, cabe recalcar que ninguno de los dos casos que se abordan aquí fueron coaliciones institucionalizadas.

\section{La Vicepresidencia y el diseño institucional argentino}

La reforma constitucional de 1994 introdujo algunas modificaciones de importancia en relación al Presidente y al Vicepresidente, aunque no fueron significativas respecto a las funciones del Vice. Estos cambios fueron: la reducción de la duración del mandato a cuatro años, la posibilidad de reelección 
inmediata por una única vez y abierta hacia el futuro, el método de elección a través de un procedimiento de doble vuelta electoral, la eliminación del requisito de confesionalidad católica y el tipo de juramento. Pero respecto de las funciones del Vicepresidente mantuvo lo establecido en el texto constitucional de $1853 / 60$.

El Vicepresidente está llamado a cubrir la ausencia temporal o definitiva del Presidente, siendo ésta su principal función. De acuerdo al artículo 88: "En caso de enfermedad, ausencia de la Capital, muerte, renuncia o destitución del Presidente, el Poder Ejecutivo será ejercido por el Vicepresidente de la Nación. En caso de destitución, muerte, dimisión o inhabilidad del Presidente y Vicepresidente de la Nación, el Congreso determinará qué funcionario público ha de desempeñar la Presidencia, hasta que haya cesado la causa de la inhabilidad o un nuevo Presidente sea electo". Respecto de la función que le asigna, el artículo 57 señala que "El Vicepresidente de la Nación será Presidente del Senado; pero no tendrá voto sino en el caso que haya empate en la votación". Brevemente, puede sostenerse que el papel asignado a la Vicepresidencia dentro del diseño presidencialista que emerge de la Constitución de 1853/60 y de la reforma de 1994 no le otorga al Vicepresidente un lugar especial más allá de la presidencia del Senado y de su puesto de reserva. Tampoco, se han producido a la largo de la historia política prácticas para - constitucionales que lo ubicaran en un lugar más relevante, como ocurrió en los EE.UU. (Serrafero 2013).

En relación con su función como Presidente nato del Senado - y más allá de la normativa constitucional - el Vicepresidente desempeña una serie de tareas y funciones que son por cierto importantes en el ámbito del Legislativo. El art. 32 del Reglamento de la Cámara de Senadores de la Nación, en sus quince incisos establece las atribuciones y deberes de su Presidente. Entre otras tareas cabe mencionar " ... $8^{\circ}$ Proveer lo conveniente a la mejor policía, orden y mecanismo de la Secretaría; $9^{\circ}$ Presentar a la aprobación de la Cámara los presupuestos de gastos y sueldos de la misma; $10^{\circ}$ Nombrar, de acuerdo a las disposiciones vigentes, a todos los empleados, y removerlos cuando halle en ellos ineptitud, desidia o desobediencia...15 $5^{\circ}$ En general, hacer observar este reglamento en todas sus partes y ejercer las demás funciones que en él se le asignan”.

En resumidas cuentas, en el diseño institucional argentino la Vicepresidencia tiene su característica función de reemplazo temporal o definitivo del Presidente y durante la coexistencia con éste es Presidente del Senado. No son demasiadas funciones - más allá de sus tareas en el Senado - y, además, no se establecen tareas en el ámbito del poder Ejecutivo. Por otro lado, no se han establecido prácticas paraconstitucionales que dotaran a la Vicepresidencia de un papel más central mientras coexiste con el Presidente. Frente a un papel normativamente reducido - en comparación con otros diseños institucionales latinoamericanos - sin presencia en el área del Ejecutivo el aumento o la reducción del papel del Vicepresidente se juegan, especialmente, en el marco de sus relaciones con la presidencia de la República. La Vicepresidencia puede ser analizada en distintos contextos, como se trata a continuación.

\section{El contexto de gobierno de los binomios}

Dos situaciones importantes para analizar la Vicepresidencia son el contexto electoral y el contexto de gobierno. En cuanto al contexto electoral, la Vicepresidencia es vista desde los motivos de designación de los candidatos, los modos y los procedimientos de selección, la elección del binomio en los comicios y todos los efectos que pueden derivarse de tales instancias. Excede los requisitos normativos para la elección de la Vicepresidencia y se interna en fenómenos netamente políticos. En el tramo electoral, el Vicepresidente es 
elegido, por lo general, sobre la base de lo que puede aportar electoralmente. Se tienen en cuenta los votos potenciales antes que la homogeneidad de proyectos y de ideas. En este contexto se puede analizar la fórmula a través de una tipología que contempla el origen político de los candidatos, su procedencia territorial, su trayectoria institucional previa, su forma de designación. Para los efectos de este trabajo sólo se consigna la composición política de la fórmula. En este sentido, de acuerdo a las fuerzas políticas representadas en el binomio, puede diferenciarse entre la fórmula mixta y la fórmula pura. La mixta es la que sella un acuerdo político o una coalición electoral entre distintos partidos y puede ser simétrica o asimétrica, de acuerdo a la fuerza electoral y el peso específico de los integrantes de la coalición. Y teniendo en cuenta la distancia ideológica de los partidos podría distinguirse entre una coalición polarizada y una moderada. En el primer caso se tratarían de distancias pronunciadas en el arco ideológico - partidario; en el segundo, primaría la afinidad o proximidad. En la fórmula pura los candidatos provienen del mismo partido. Puede ser absoluta o relativa, según representen, o no, el mismo sector interno de la fuerza política.

En relación con el binomio y el "contexto de gobierno" se trata de los modos de coexistencia entre Presidente y Vice mientras están ambos en sus funciones, la relaciones que entre ellos pueden tejerse y desarrollarse, y sus distintas consecuencias. Una vez que los candidatos electos asumen, se ingresa así en el contexto de gobierno y aquí cuentan las ideas, los estilos y la relación entre ambos. Existen distintas formas de vinculación, actitudes y comportamientos de acercamiento y distanciamiento - de los componentes de la fórmula. En el siguiente cuadro aparece una tipología básica que intenta dar cuenta de la identificación y lealtad de la Vicepresidencia. Así, puede decirse que la identificación y lealtad total es lo que se ha denominado fórmula solidaria absoluta. Pero parece que, en los hechos, es difícil que ocurra, salvo en los tramos muy iniciales de las administraciones. Por el contrario, es probable que aparezcan fórmulas menos solidarias que podríamos denominar, según los supuestos: solidarias relativas, cuando el Vicepresidente implícitamente parece concordar con la línea presidencial, aunque no se expida o bien no sea partícipe activo de sus políticas; solidarias críticas, cuando se establecen claramente las diferencias con el Presidente en determinadas cuestiones importantes, sin que ello signifique una oposición total a sus políticas. Y también podrían encontrarse fórmulas no solidarias: la no solidaria - moderada, cuando las diferencias existentes son significativas en número y contenido político, existe tensión, pero no llegan al conflicto manifiesto; y la no solidaria - polarizada, cuando la distancia ideológica y/o de estilo político es máxima y se llega a la emergencia de conflictos graves.

Así una gradación sobre los tipos de solidaridad sería: a) solidaridad absoluta; b) solidaridad relativa; c) solidaridad crítica; d) no solidaridad-moderada; e) no-solidaridad polarizada. En el Cuadro 1 se ilustra la tipología propuesta en relación con el contexto o fórmula de gobierno y la probable actitud de "lealtad" del Vicepresidente.

En las diferentes fórmulas del contexto de gobierno encontramos distintos tipos de Vice y de climas de relación entre Presidente y Vicepresidente. En las fórmulas solidarias (absoluta, relativa y crítica) encontramos Vices colaboradores (activos, pasivos y críticos) y en las fórmulas no solidarias Vices opositores (moderados o extremos). Los climas que se desarrollan respecto de la relación pueden ser de confianza, cordialidad, desconfianza, tensión y conflicto (Cuadro 2).

El colaborador activo concuerda con todas las políticas del Presidente, por el sólo hecho de ser planteadas por el mandatario. Además, realiza una defensa 
Cuadro 1 - Tipología del contexto de gobierno

\begin{tabular}{lcc}
\hline Formula de Gobierno & $\begin{array}{c}\text { Actitud esperable del } \\
\text { Vice }\end{array}$ & Tipo de Lealtad \\
\hline Formula solidaria & Absoluta & Lealtad activa y total \\
& Relativa & Lealtad pasiva \\
& Crítica & Lealtad condicionada \\
Formula no solidaria & Moderada & Lealtad improbable \\
& Polarizada & Falta de lealtad. Conflicto \\
\hline
\end{tabular}

Fuente: Elaboración propia.

Cuadro 2 - Tipo de Vice y clima de la relación Presidente - Vice

\begin{tabular}{lcc}
\hline Solidaridad/No solidaridad & Tipo de Vice & Clima de la relación \\
\hline Solidaridad Absoluta & Colaborador Activo & Confianza \\
Solidaridad Relativa & Colaborador Pasivo & Cordialidad \\
Solidaridad Crítica & Colaborador Crítico & Desconfianza \\
No solidaridad moderada & Opositor Moderado & Tensión \\
No solidaridad polarizada & Opositor extremo & Conflicto \\
\hline
\end{tabular}

Fuente: Elaboración propia.

pública de esas posiciones o, a lo sumo, puede callar respecto de las que eventualmente no esté de acuerdo, pero seguramente si es preguntado por la prensa también asentirá. Durante la coexistencia en el gobierno no tiene distancia ideológica con el Presidente. Realiza todos los pedidos que le encomienda el mandatario y evita a toda costa tener conflictos con el Presidente.

El colaborador pasivo concuerda las políticas esenciales del Presidente. Además, no es un militante que realice una defensa pública y constante de las políticas presidenciales, aunque no suele criticarlas. Tiene un perfil bajo y se limita sobre todo a cumplir su rol institucional. Puede también realizar las tareas encomendadas por el Presidente. Mientras están en el gobierno no tiene prácticamente distancia ideológica con el mandatario. No suele tener problemas o conflictos pues decide mantener una relación cordial con el Presidente y evitar problemas.

El colaborador crítico acuerda con las políticas del Presidente, pero cuestiona críticamente aquellas con las cuales no concuerda. Sus opiniones, tanto en favor como en contra las hace públicas, o las deja trascender. Durante la coexistencia en el gobierno la distancia ideológica resultará de sus acuerdos, pero también de su falta de coincidencias con el Presidente. Realiza todos los pedidos que le encomienda el mandatario, siempre y cuando no sean materia de cuestionamientos. Evita tener conflictos con el Presidente, pero pueden ocurrir respecto de los temas o políticas concretas en disidencia.

El opositor moderado no concuerda con la mayoría de las políticas presidenciales. Pero no hace una exposición pública de los desacuerdos que mantiene con el mandatario. Podrá llegar a cumplir algunos de los pedidos que le haga el Presidente, pero no es esperable que se lo tenga en cuenta. Tiene una distancia ideológica considerable con el Presidente. Ha tenido conflictos con el mandatario. El perfil es bajo y la relación permanece como congelada o en conflicto latente. 
El opositor extremo tiene un desacuerdo prácticamente total y frontal con todas las políticas del Presidente. Cuando puede o lo considera pertinente realiza un ataque público de las posiciones del mandatario. No cumple los pedidos del Presidente y la distancia ideológica entre ambos se profundiza cada vez más. Los conflictos son manifiestos y persistentes.

Al tratarse de una "relación" no estaría completo el panorama sin incluir la actitud del Presidente hacia el Vice. Es posible encontrar, al menos, tres tipos de mandatarios (Cuadro 3) . El Presidente Incluyente, que participa al Vice de su equipo de trabajo o entorno político. El Presidente Indiferente que prescinde del Vice al cual lo relega básicamente al cumplimiento de sus funciones constitucionales. Y el Presidente Excluyente que está activamente interesado en excluir al Vice de los espacios políticos propios, trata de aislarlo. ¿Qué factores pueden incidir para que se den los distintos tipos? Es probable que el Presidente Incluyente exista cuando: a) ha intervenido directamente en la designación de su Vice; b) el Vice pertenezca a su grupo de trabajo; c) haya tenido conocimiento e interacción con su Vice antes de su designación; d) compartan mínimos contenidos ideológicos. Por el contrario, sería más esperable un Presidente Excluyente cuando el Vice: a) no haya sido designado por el mandatario, b) existiera poco conocimiento previo entre ambos, c) la distancia ideológica sea considerable. Podría un Presidente pasar de un tipo a otro en la medida en que los factores referidos se modifiquen a lo largo de la interacción durante el contexto de gobierno.

Entre los comportamientos que caracterizan a un Presidente Incluyente encontramos: la reunión periódica con el Vice para evaluar la marcha del gobierno, la presencia del Vice en reuniones de gabinete, su incorporación en la "mesa chica" o bien la consulta de la opinión del Vice para la toma de decisiones, como una suerte de adviser de primer orden. El Presidente Indiferente tiene una actitud prácticamente prescindente respecto del Vice. El Vicepresidente puede concurrir a las reuniones de gabinete, pero principalmente cumple sus funciones en el Senado. Prácticamente el Presidente no le delega cuestiones y tampoco lo consulta y, si lo hace, es sólo esporádicamente. En relación con el Presidente Excluyente, cabe señalar que no se reúne nunca con el Vice para evaluar la gestión de gobierno, el Vice es excluido de las reuniones de gabinete, no se le transmite información de la "mesa chica" donde se toman las decisiones, ni se lo consulta. Suele enterarse de los asuntos más importantes a través de los medios. En otras palabras, el Presidente lo excluye de la esfera ejecutiva, no lo consulta para la toma de decisiones y puede, incluso, llegar a hostilizarlo.

En el contexto de gobierno la relación requiere un clima de confianza o cordialidad entre Presidente y Vicepresidente. Estos climas necesitan un Presidente Incluyente de la figura de la Vicepresidencia en su gobierno y un

Cuadro 3 - Tipo de Presidente en relación con el Vicepresidente

\begin{tabular}{ll}
\hline $\begin{array}{l}\text { Tipo de Presidente en relación } \\
\text { con el Vice }\end{array}$ & Características \\
\hline Presidente Incluyente & $\begin{array}{l}\text { Incluye al Vicepresidente dentro de su equipo de } \\
\text { gobierno como asesor o miembro destacado de su } \\
\text { entorno }\end{array}$ \\
Presidente Indiferente & $\begin{array}{l}\text { Actitud de indiferencia y/o prescindencia. El } \\
\text { Vice cumple sólo sus funciones constitucionales. }\end{array}$ \\
Presidente Excluyente & Aísla al Vicepresidente no sólo de su equipo y \\
& entorno sino que trata de encapsularlo y aislarlo. \\
\hline
\end{tabular}

Fuente: Elaboración propia. 
Vicepresidente que sea colaborador del Presidente. Si estas actitudes y/o comportamientos de Presidente y Vice no se logran, la relación ingresa en un clima de desconfianza, tensión o conflicto.

Cuando se trata de una fórmula pura (absoluta o relativa) que implica una fórmula de un partido en el gobierno, las consecuencias del clima de desconfianza, tensión o conflicto entre Presidente y Vice podrán derivar en situaciones de aislamiento del Vicepresidente por parte del Presidente, o de intentos de no cooperación y hasta de desestabilización del Vice. Pero si se trata de una fórmula mixta que sella una coalición electoral, es probable que la coalición ingrese en una disolución progresiva y hasta en su desintegración, salvo que el Vice no sea una figura relevante en su partido o bien existan arreglos relativamente sólidos entre los partidos que conforman la coalición.

Es complejo delinear los efectos de las interacciones de acuerdo a tipos básicos de Presidente y Vice (Cuadro 4); pero si puede brindarse una probable reacción de la otra parte, según fuere la actitud o comportamiento que se va desarrollando entre los dos actores.

Es probable que un Presidente Incluyente promueva la emergencia de un Vice colaborador activo y, a su vez, un Vice que se muestra como fiel y activo militante de las políticas del Presidente, obtenga mayor inclusión por parte de éste, en su equipo de gobierno. Un Presidente Indiferente podría provocar desde una colaboración pasiva y crítica hasta una oposición moderada por parte del Vice. De igual modo, un Vice que se muestra poco o casi nada comprometido puede generar la indiferencia del mandatario. Y un Presidente Excluyente es más probable que genere un Vice opositor moderado o extremo, al igual que un Vice que desafía al Presidente obtendrá la exclusión como respuesta o el intento de que renuncie al cargo. Estas probabilidades dependen por cierto de la personalidad y estilo, tanto del Presidente como del Vice, de la situación política que obra como contexto de la relación y de la dinámica de interacción entre ambos. Así, puede ocurrir cierto desplazamiento en el sector (B), pero poco probable en (A) y (C). No es previsible que un Vicepresidente opositor extremo sea incluido en el círculo íntimo del poder presidencial, como que un Vicepresidente fiel y activo sea excluido absolutamente por el mandatario. Pero este esquema de probabilidades de comportamiento está abierto a otras opciones como se vio en el caso Kirchner - Scioli, donde el "pago" de Kirchner -Presidente Indiferente - a la obediencia absoluta de su Vice fue ofrecerle una candidatura futura, sin incluirlo en su equipo cercano de gobierno mientras fue mandatario. Si se trata de un Presidente Indiferente o Excluyente que tiene popularidad o éxito podrá coexistir con un Vice colaborador que sentirá o calculará que se beneficia de la popularidad presidencial, aunque el mandatario prácticamente no lo tenga en cuenta o lo excluya de su círculo más cercano.

La interacción entre Presidente y Vice no es estática, sino dinámica. La relación suele construirse a través de un feed - back que obedece a distintos puntos de origen vinculados a las tipologías referidas (y difíciles de ser precisados). Pero una situación o conjunto de hechos pueden marcar un punto de

Cuadro 4 - Interacción Presidente - Vice

\begin{tabular}{ll}
\hline Tipo de Presidente & Tipo de Vicepresidente \\
\hline Presidente Incluyente (A) & Vicepresidente colaborador activo \\
Presidente Indiferente (B) & $\begin{array}{l}\text { Vicepresidente colaborador pasivo Vicepresidente } \\
\text { colaborador crítico Vicepresidente opositor moderado }\end{array}$ \\
Presidente Excluyente (C) & Vicepresidente opositor extremo \\
\hline
\end{tabular}

Fuente: Elaboración propia. 
inflexión a partir del cual la relación puede cambiar de sentido. Generalmente, un conflicto importante puede ser el primer paso del cambio de interacción entre ambos. A continuación, se tratan los casos en estudio.

\section{De la Rúa - Álvarez (y el fracaso de una coalición)}

Un formato bipartidista (radical - peronista) existió en la Argentina, básicamente, entre 1983 y 1993. La formación del Frepaso y los resultados electorales de 1995, debilitaron el bipartidismo con el nuevo actor en escena. Dos años más tarde, la unión entre el Frepaso (Frente País Solidario) y la UCR (Unión Cívica Radical) implicó no sólo una importante disminución de los votos obtenidos por el justicialismo en las elecciones legislativas de 1997, sino también una fuerte variación de expectativas que se tradujeron en el triunfo de la Alianza en 1999. La conformación de la Alianza, en agosto de 1997, fue un ingreso de aire fresco para la política argentina. Un radicalismo debilitado y un Frepaso en ascenso - gracias al Pacto de Olivos entre el peronismo y el radicalismo, que permitió la reforma constitucional de 1994 - se unieron como eje contrapuesto a distintos comportamientos mostrados por el menemismo, entre otros, falta de transparencia y corrupción. El resultado electoral en las elecciones de 1997 mostró un peronismo en declive que obtenía el 36,27\% de los votos, una Alianza que lograba el $36,26 \%$ y que, sumados los votos radicales y frepasistas que habían concurrido en soledad evidenciaba una diferencia del 9,38\%. La coalición triunfó en los distritos más poblados de Buenos Aires, Santa Fe, Córdoba y la Ciudad Autónoma de Buenos Aires.

La nueva coalición, más allá de haber criticado los comportamientos del modo de hacer política del justicialismo centrado en la mera acumulación de poder más que en el "buen gobierno" - de todos, para todos y cuyo fin es el "bien común" - a poco de andar los miembros de la Alianza mostraron un apetito no muy diferente. La mesa de conducción se conformó con los líderes del radicalismo (Alfonsín, De la Rúa y Terragno) y del Frepaso (Meijide y Alvarez). La discusión sobre la repartición de cargos y distritos estuvo en los inicios de las negociaciones. La fórmula presidencial debía decidirse en una interna abierta entre el candidato de cada agrupación fundante de la Alianza. El triunfador tendría la presidencia y la Vicepresidencia quedaría en manos del otro partido. Un consenso sobre la mínima geometría de poder electoral y de gobierno, concluía que el partido que perdiera la candidatura presidencial, tendría la candidatura principal en el distrito de la Ciudad de Buenos Aires y de la Provincia del mismo nombre. Así se lograría el equilibrio interno a través de un balance de poder que conectara lo institucional con lo interpartidario (aliancista). Compitieron Fernando de la Rúa por el radicalismo y Graciela Fernández Meijide por el Frepaso. Triunfó el candidato radical, quien fue finalmente el candidato presidencial y la Vicepresidencia quedó para el Frepaso quien pondría en ese puesto a Carlos "Chacho" Alvarez. Fernández Meijide pasaba a competir por el importante distrito de la Provincia de Buenos Aires.

La fórmula De la Rúa - Álvarez se trataba de un binomio poco experimentado en el campo ejecutivo, Álvarez sin ninguna experiencia y De la Rúa con una trayectoria muy limitada en ese terreno, en la Jefatura del gobierno de la Ciudad de Buenos Aires. El perfil de ambos era legislativo, con todo lo que ello implicaba. De alguna manera era previsible cierto déficit en la acción gubernativa, tanto en lo referido a la toma de decisiones como en la implementación, seguimiento y rectificación de las políticas públicas. El déficit podría haberse superado con una selección de equipo de gobierno con experiencia y coherencia. El Gabinete con el cual arrancó la Alianza, sin duda, se integró con figuras de notorio prestigio y reconocida trayectoria, pero en cuanto al desempeño previo en algún ministerio nacional sólo contaba con esa experiencia el Jefe de 
Gabinete, Rodolfo Terragno y Juan Llach quien se había desempeñado como Viceministro de Economía en parte del gobierno del ex Presidente Menem, cuando Cavallo era titular de la cartera.

La procedencia política de los integrantes de la fórmula es el criterio más importante en el análisis de la fórmula. La distancia ideológica entre Presidente y Vice era importante, y durante la gestión se profundizó. En este sentido, no había duda de que, entre De la Rúa y Álvarez no existía una identificación plena de idearios o ideologías, sino se sabía desde un principio que el Presidente se ubicaba en el sector más conservador del radicalismo. Álvarez representaba a la centro - izquierda en el arco político nacional y, en su momento, se había escindido del peronismo no sólo por la corrupción sino por el modelo "neoliberal" que implicaba - en su entender - la política del ex Presidente Carlos Menem.

El propio Álvarez señaló en relación con De la Rúa y la distancia ideológica entre ambos, dos años después de su renuncia: "Debo confesar que mi sociedad política con De la Rúa es imperdonable. Tuve una confusión injustificada entre un moderado y un conservador... era un hombre muy comprometido con lo peor de la Argentina" (Mi sociedad política con De la Rúa... 2002, p.4). En realidad, pocas dudas podían caber acerca del perfil conservador (Fernández Meijide 2007) del ex Presidente. Asimismo, cabe señalar que no hubo demasiada resistencia del Frepaso respecto de la composición y el sesgo conservador del gabinete inaugural de la Alianza (Jozami 2004). La distancia ideológica entre Álvarez y De la Rúa era, entonces, bastante pronunciada. Tampoco el radicalismo y el Frepaso mostraban una fina sintonía en cuestiones de fondo, más allá de los esfuerzos de querer mostrarse encolumnados tras ciertos objetivos.

Álvarez ocupó un despacho en la Casa Rosada, el mismo que había tenido el ex Vicepresidente Carlos Ruckauf. El Presidente había señalado que no quería tener un Vice decorativo y, en este sentido, Álvarez realizaría tareas en la lucha contra la corrupción y en la reforma política. El perfil que desempeñó durante su gestión fue alto. Tuvo reuniones con académicos y Organizaciones No Gubernamentales para poner en marcha el programa de "Auditoria Ciudadana de la Calidad Institucional”. Realizó viajes diplomáticos al exterior, participó en actos protocolares, seminarios y eventos institucionales. Concurría siempre a las reuniones de gabinete. Cuando el Presidente viajaba al exterior ejercía el Poder Ejecutivo y desarrollaba una profusa actividad (Shribman 2009).

¿Qué tipo de Presidente fue De la Rúa? Si bien había dicho que quería un Vicepresidente activo, las declaraciones de Álvarez lo contradicen. Respecto a las reuniones sobre la marcha de la coalición de gobierno señaló: "Las pocas veces que evaluamos juntos aspectos de la marcha del gobierno fueron en los momentos inmediatamente posteriores al inicio de la gestión. Era necesario apelar de mi parte a gestos dirigidos a crear confianza, para que comprendiese que nos sentíamos totalmente jugados al éxito del gobierno. Pero debo admitir la dificultad de dialogar con una persona extraña, cuyo pensamiento había que descifrar a través de gestos, movimientos, o de la prolongación de silencios interminables" (Álvarez \& Morales Solá 2002, p.103).

Según el Vicepresidente, la indiferencia presidencial se extendía también respecto de los temas que habían quedado como de su órbita o interés. Decía Álvarez: "Quería colaborar junto al jefe de gabinete y el ministro del Interior en dos temas que consideraba claves: la reforma del Estado y la reforma política. Nunca supe sinceramente si el Presidente respaldaba mi labor o no. Y esto lo digo porque en los diez meses que compartimos el gobierno nunca me preguntó absolutamente nada sobre cuáles eran los planes, quiénes conformaban el equipo, qué resultados se esperaba alcanzar y en qué tiempo. El jefe de Estado se encontraba absolutamente distante" (Álvarez \& Morales Solá 2002, p.95). 
Álvarez describía a Fernando de la Rúa, claramente, como un Presidente Indiferente.

Con el transcurrir de los meses la relación entre De la Rúa y Álvarez se fue deteriorando. No hay espacio aquí para consignar en detalle la dinámica de este proceso. Si como sucede habitualmente al inicio de una gestión existía solidaridad entre Presidente y Vice, con el correr de los meses se fue deteriorando la confianza mutua y aparecieron las diferencias profundas.

Se trataba de una fórmula - y coalición - asimétrica, quien debía preocuparse más para revertir la asimetría era la parte débil, que era el Frepaso, representada por Carlos "Chacho" Álvarez. En otros términos, debía desde su rol de Vicepresidente equilibrar las partes de la coalición, esto era, lograr una mayor institucionalización del Frepaso y su crecimiento.

El Vicepresidente, en el Senado, se encontró con senadores peronistas que no le tenían singular aprecio y con senadores radicales que veían en él aquel peronista que había sido. La confianza y buena relación que existía con el Presidente en tiempos de la campaña y al principio del gobierno de la Alianza se fue deteriorando, principalmente, por las declaraciones y acciones del Vicepresidente. Los ejemplos se fueron multiplicando en el año 2000. Su primera denuncia relevante fue la presencia de "ñoquis" -personas que cobraban sueldo sin trabajar - en el Senado. Luego vendría la denuncia sobre corrupción respecto de la sanción de la ley de reforma laboral en ese ámbito. También hay que agregar que al Vicepresidente le molestaron las supuestas filtraciones de la Secretaría de Inteligencia (SIDE) - que dependía de la presidencia de la nación sobre aspectos de su vida personal. Por otra parte, ya existían divergencias entre el Presidente y el Vice sobre el diagnóstico de la situación social y económica (Shribman 2009).

En cuanto a la "lista de ñoquis", previamente, Álvarez había intentado que los empleados del Congreso se incluyeran dentro de la rebaja de los sueldos públicos que había determinado el Ejecutivo. Pero allí encontró la resistencia de los senadores. Quizá como contrapartida destapó un asunto que por cierto tenía larga data. Su denuncia no involucraba sólo a los peronistas, sino también a los radicales. Para Álvarez debían ser transparentadas todas estas prácticas viniesen de donde viniesen. Se encontró así con la resistencia del partido del Presidente que, supuestamente, había sido parte del sistema habitual de funcionamiento de la Cámara Alta.

El principal conflicto se originó en torno de los supuestos sobornos en el Senado. En el mes de junio de 2000 el periodista Joaquín Morales Solá publicaba una nota en el diario La Nación que encendía la polémica y donde se decía: "habrían existido favores personales de envergadura a los senadores peronistas - para sorpresa de algunos - después de que estos aprobaran la reforma laboral; esas concesiones fueron conversadas y entregadas por dos hombres prominentes del gobierno nacional... ¿Qué línea prevalece? ¿La de aquellos favores a cambio del voto para una ley o la del Vicepresidente Carlos Álvarez, que viene denunciado a los senadores peronistas y a la corporación senatorial por el uso que ésta hizo de los recursos de la Cámara?" (Joaquín Morales Solá, Carencias y defectos).

El Vicepresidente reclamó el alejamiento de los senadores más sospechados y el apoyo político del Presidente. De la Rúa señalaba que desde el gobierno no se había pagado suma alguna en relación a los presuntos sobornos en el Senado para el trámite de la ley de reforma laboral. Álvarez expresaba, en cambio: "En un soborno alguien cobra y alguien paga, como en un tango donde bailan dos. Pagaron sectores del Gobierno" (Fernando Laborba, La escena contradictoria). 
Las declaraciones y actitudes de Álvarez habían provocado el recelo del radicalismo. El Vicepresidente no hizo mayores distinciones entre peronistas y radicales a la hora de criticar las supuestas prácticas corruptas del Senado. Los senadores radicales y otros sectores del partido vieron cada vez con mayor desconfianza a Álvarez. Por el lado del Frepaso, se cuestionó no sólo la corrupción, sino también la política económica del gobierno que se desviaba ostensiblemente de lo que había sido el discurso de campaña. En realidad, Álvarez había partido de una situación de acuerdo con el Presidente en cuanto al rumbo económico de la nueva administración. Álvarez parecía estar más allá de las cuestiones partidarias. Lo suyo era el mantenimiento de su perfil ético en coincidencia con el aprovechamiento pleno de la relación con los medios.

Frente a la situación, De la Rúa realizó un cambio de gabinete que implicaba premiar a los cuestionados por el Vice y, lo peor, el cambio aparecía como inconsulto y con la intención de dejar sentada la primacía del liderazgo presidencial. Pocas horas después renunciaba el Vicepresidente. Las declaraciones de Álvarez ilustran el tipo de relación que existió previamente a su ruptura. El día clave fue cuando juraron los nuevos ministros, cuya designación no había sido consultado con el Vice. Decía Álvarez tiempo después: "El punto culminante fue la jura de los nuevos ministros, por la tarde, donde el clima de afianzamiento de la impunidad política fue elocuente y fuertemente simbólico... Mi renuncia podía ser una de las consecuencias esperadas por el entorno de De la Rúa. ¿Qué rol desempeñaba yo en un gobierno donde, desde el centro de la decisión, se me comenzaba a caracterizar como enemigo? ¿Qué papel podía tener cuando, en lugar de fortalecerse una salida conjunta de la Alianza, se trataba de humillar y dejar sin margen de acción al socio principal?" (Álvarez \& Morales Solá 2002, p.45). Continúa señalando Álvarez: "En ese momento evalué el posible desquicio institucional que hubiese sido un escenario donde, por un lado, hay un Presidente percibido como dubitativo y débil, que ampara a los sospechosos y, por otro, el Vicepresidente, líder de la otra fuerza política de la coalición, convoca a movilizarse contra los tres poderes del Estado. Esto implicaba, concretamente, movilizar contra la política de impunidad que apoyaba el Presidente, contra los sobornos en el Senado y la inoperancia de la Justicia para investigar el hecho. Si ya antes de los hechos del Senado los medios de comunicación advertían sobre los peligros de un poder bifronte, una movilización contra el gobierno se hubiese interpretado como un choque institucional insostenible. Más temprano que tarde, eso terminaba en la fractura de la Alianza y en mi renuncia, que de todos modos se hacía inexorable. Tomé conciencia de la imposibilidad de continuar en un cargo que, sin más diálogo con el Presidente, era decididamente intrascendente, pero con la suficiente exposición pública como para ser un factor de permanente conflicto institucional" (Álvarez \& Morales Solá 2002, pp.47-48).

Álvarez señalaba la amenaza que resultaría de un poder "bifronte", pero además el conflicto que se instalaba era más extenso. En realidad, su apreciación sólo tenía por horizonte el corto plazo, esto es el contexto de gobierno. Desde el contexto de sucesión su posición era expectable.

El párrafo transcripto resulta muy claro respecto de la actitud y las ideas institucionales del entonces Vicepresidente. Álvarez había pasado de la fórmula solidaria a una no solidaria convirtiéndose en un Vicepresidente opositor. Podría haberse mantenido en una actitud crítica (fórmula solidaria crítica), señalando las diferencias con la presidencia, pero sin ubicarse en una situación de opositor. La alternativa que se planteó y que - según su argumentación - lo pondría en franco enfrentamiento al recurrir a la movilización ciudadana era la de una fórmula no solidaria polarizada. Álvarez se enfrentaba a un dilema: 1) Si se iba de la Vicepresidencia, el ocaso de la Alianza era indefectible como así también la debilidad progresiva de su fuerza política, el Frepaso; 2) si se 
quedaba en su puesto, debería haberse adaptado a una nueva situación para él: mantenerse en situación de crítica, pero sin recurrir a la permanente denuncia mediática. En la situación 1) debilitaba al gobierno y sembraba la semilla de la involución del Frepaso. En la situación 2) mantenía abierta la posibilidad de rectificación del gobierno, sostenía a su fuerza en un estado más saludable y se constituía en "reserva" ante una posible crisis de gobierno.

La Vicepresidencia es una institución de crisis, no de gobierno, en el caso argentino esto es bien claro, en otros ordenamientos constitucionales latinoamericanos el Vicepresidente cuenta con algunas funciones en el ámbito del Poder Ejecutivo. Si en el esquema de coalición debió jugar un papel que el Presidente le escatimaba, la potencialidad de la figura se hubiera extendido al compás de la profundización de la crisis. El cargo de Vicepresidente es más adecuado para los políticos pacientes y racionales y no encaja con los ansiosos y sanguíneos.

Con la renuncia de Carlos Álvarez a la Vicepresidencia se produjo la primera gran crisis del gobierno de coalición de la Alianza. Inútil fue que el Vice dijera que la coalición permanecía. Progresivamente se fue diluyendo y desintegrando. El gobierno se debilitó cada vez más y se produjo una dinámica que concluyó con la renuncia del Presidente Fernando de la Rúa produciéndose una de las crisis más profundas de la historia argentina.

\section{Cristina - Cobos (y el naufragio de un acuerdo político)}

La fórmula Cristina Fernández de Kirchner - Julio César Cleto Cobos si bien no era expresión de una coalición electoral conformaba, en cambio, un acuerdo entre el oficialismo y un sector del partido radical denominado los "radicales K”. En 2006 se hablaba de la preferencia que el Presidente Néstor Kirchner tenía hacia el gobernador mendocino, Julio César Cleto Cobos, quien pertenecía al referido grupo. Kirchner quería cerrar un acuerdo con este sector y ofrecer la Vicepresidencia a un político radical. Cobos dejaría el gobierno mendocino pues la Constitución provincial prohibía la reelección y su designación como Vice sellaba la "Concertación Plural". Néstor Kirchner y Cobos habían desarrollado una relación cordial durante sus gestiones al frente del ejecutivo nacional y provincial, respectivamente. Por otro lado, Cobos tenía un perfil bajo que aparecía como complementario del carácter fuerte atribuido a la candidata y con su designación - siendo del interior - supuestamente, se acentuaba el carácter federal de la fórmula. Durante la campaña electoral Cobos había adelantado que en el gobierno se veía en un papel activo como un "articulador de consensos". El papel que se imaginaba Cobos era congruente con el lema de campaña que lo incluía expresamente: "Cristina, Cobos y vos". Pero el kirchnerismo fue forjando su propia interpretación sobre los alcances de la Vicepresidencia que no encajarían con los deseos de Cobos.

Cristina Fernández de Kirchner (CFK), a diferencia de su marido, tuvo una trayectoria política institucional en el ámbito legislativo. Por la provincia de Santa Cruz había sido electa diputada provincial en 1989 y reelecta en 1993, senadora nacional en 1995, diputada nacional en 1997 y nuevamente senadora nacional en 2001. En 2005 fue elegida Senadora Nacional por la Provincia de Buenos Aires. Su Vicepresidente, Julio Cobos, representaba la cara opuesta pues se había desempeñado sólo en cargos ejecutivos. Había sido Subsecretario de Urbanismo y Vivienda de la ciudad de Mendoza (1994 - 1997); Secretario de Obras Públicas de la referida ciudad (dic. 1999/dic. 2000) y Gobernador de Mendoza, 2003-2007. Se trató de una fórmula mixta que selló un acuerdo electoral con un sector del radicalismo, y fue de carácter asimétrico dado las diferencias de tamaño y organización entre el kirchnerismo y los radicales $\mathrm{K}$. En realidad, se inscribió dentro de la tradición "frentista" del peronismo y cabe 
recordar aquí las fórmulas de Juan D. Perón con Juan Hortensio Quijano de la Unión Cívica Radical - Junta Renovadora, en 1946 y 1951, y la fórmula de 1973 cuando Héctor J. Cámpora fue acompañado por Vicente Solano Lima, del partido Conservador Popular.

El 28 de octubre de 2007, la formula CFK y Julio Cobos superó el 45\% de los votos, en segundo lugar se ubicó Elisa Carrió - Rubén Giustiniani con la Coalición Cívica, que obtuvo el 23\% de los sufragios. La nueva presidenta presentó a su gobierno como una continuidad del de su marido, pero la campaña también agregaba el slogan "sabemos lo que falta, sabemos cómo hacerlo".

El Vicepresidente Cobos pasó a desempeñarse en la presidencia del Senado, cumpliendo sus funciones constitucionales y con la intención de abocarse al plan de fortalecimiento institucional. La presidenta CFK no tenía la intención de incluirlo en la esfera del Ejecutivo. No tuvieron encuentros de evaluación de la marcha del gobierno y como no había reuniones de Gabinete de ministros, el Vicepresidente tampoco contaba con información directa de la gestión de las carteras ministeriales. La exclusión del Vicepresidente iba a empeorar rápidamente.

A los pocos meses de iniciada la nueva administración sucedió un grave conflicto con sectores rurales. El paro agropecuario se había iniciado el 11 de marzo de 2008 y extendido por más de cuatro meses con bloqueo de rutas, entre otras medidas. Las cuatro organizaciones que representaban al sector - la "mesa de enlace" - protestaban por la resolución 125 que incrementaba las retenciones de soja y girasol y establecía un sistema de retenciones móviles. El 15 de junio, cuando la situación estaba extremadamente tensa y en un punto muerto, Cobos hizo pública una carta remitida a la presidenta señalando que el Congreso debía intervenir en la resolución del conflicto. Al día siguiente la presidenta decidió remitir un proyecto de ley para que sea el Congreso quien se expidiera sobre el proyecto que sería remitido por el Ejecutivo.

Los rumores de renuncia del Vicepresidente recorrieron los pasillos políticos. Ante la pregunta sobre si había pensado en renunciar, Cobos dijo en una entrevista: "Nunca, sería una deshonra para la ciudadanía que me votó... Yo presido otro poder. Si bien el Vice se elige en forma conjunta yo represento otro sector, no soy del PJ (Partido Justicialista) y, además, presido el Senado de la Nación" (Cobos: "Hay que buscar no sólo votos" 2008). Otra declaración de Cobos ocasionó un nuevo malestar al gobierno, cuando señalaba que: "hay que buscar no sólo votos sino consensos, respetar la pluralidad de ideas... Hay una muy buena predisposición de la oposición" (ibid.). El ministro del Interior, Florencio Randazzo señaló respecto de Cobos, “el Vicepresidente de la Nación es miembro del Poder Ejecutivo Nacional y su preocupación debe concentrarse en preservar los intereses del poder que representa... El gobierno desea que sus legisladores, y su Vicepresidente, acompañen a su presidenta, sin buscar votos" (ibid.).

El proyecto remitido al Ejecutivo consistía, esencialmente, en la ratificación de la resolución 125 que había originado el conflicto. El ministro de Justicia, Aníbal Fernández, públicamente señalaba que el Congreso debía expedirse por sí o por no y a libro cerrado sobre el contenido del proyecto. Los días fueron pasando y la reacción de la oposición y de los legisladores del propio partido modificó la postura inicial de considerar al Congreso como mero órgano de ratificación y no instancia deliberativa. Por ese entonces ya se hablaba de las intenciones desestabilizadoras y "destituyentes" que tenía la protesta rural en sociedad con el grupo Clarín. Luis D’Elía - un activista alineado con el gobierno - los acusaba públicamente de "golpistas" y "oligarcas". 
El viernes 4 de julio comenzó el debate en la Cámara de Diputados y en una maratónica sesión que insumió 19 horas y 154 oradores, finalmente fue aprobado el proyecto oficial, pero con numerosas enmiendas que fueron necesarias para llegar al número. En realidad se trató de una victoria muy escueta. De 253 votos, por el sí se expidieron 129 y por el no, 122 y hubieron dos abstenciones. La diferencia a favor del oficialismo fueron sólo 7 votos. La cuenta arrojó un dato preocupante para el gobierno: 19 votos del kirchnerismo y sus aliados no acompañaron el proyecto ( 15 del Frente para la Victoria y 4 de radicales K).

En vistas al tratamiento del proyecto en el Senado el campo decidió movilizarse y la mesa de enlace fijó un acto para el 15 de julio. El ex Presidente Néstor Kirchner convocó otro acto, el mismo día y a la misma hora, en frente del Congreso. El campo y el gobierno llevaron así su competición a las calles, siendo el sector rural quien más público congregó. Al día siguiente la sesión en el Senado comenzó a las 10,30 horas, intervinieron 54 legisladores y la jornada duró 18 horas. Las cifras de la votación dejaron al kirchnerismo en un escenario tan incómodo como dificultoso: 36 votos a favor y 36 en contra. Debía decidir, nada más y nada menos que el denostado Vicepresidente.

Cobos frente a la situación de empate manifestó que era el día más difícil de su vida y propuso un "cuarto intermedio" con el fin de que los legisladores llegaran a un acuerdo. Pero el Presidente del bloque oficialista, senador Pichetto y el del radicalismo, senador Sanz, rechazaron la propuesta del Vicepresidente. Cobos, entonces, comenzó un discurso que evidenció el peso que para él tenía su voto. Dijo: "No creo que esto sea motivo para poner en riesgo el país, la gobernabilidad, la paz social. Quiero seguir siendo el Vicepresidente de todos los argentinos... La Presidente de los argentinos va a entender... No puedo acompañar" (Gustavo Ybarra, Tras una dramática sesión). Su voto fue en contra del proyecto oficialista. Señalaba: "la historia me juzgará no se cómo. Pido perdón si me equivoco. Mi voto no es positivo". Al igual que lo ocurrido en el caso del ex Vicepresidente Scioli, tras los hechos del campo, los políticos seguidores de Cobos que ocupaban puestos en el organigrama del gobierno tuvieron que dejar sus cargos. El Vicepresidente había dejado de ser un crítico para pasar a convertirse en un Vicepresidente opositor, como iba a demostrarse en hechos posteriores.

Cobos había sido expulsado del partido radical por su alianza con Kirchner. Luego de su posición frente a los hechos del campo la conducción radical fue menos severa con él y comenzó su gradual retorno a las filas radicales. El Vicepresidente se convirtió en referente político y una figura buscada por los medios de comunicación. Dio su opinión sobre casi todos los temas que surgían en la política cotidiana estando de acuerdo o discrepando con las políticas del ejecutivo. Se convirtió en referente político y abrigó incluso deseos de una futura presidencia.

El conflicto con el campo y su modo de resolución sería un momento bisagra no sólo para el Vicepresidente, sino también para el kirchnerismo. Para el gobierno el traspié había sido producto de los medios "hegemónicos" que daban una visión interesada y distorsionada de la realidad. Los resultados electorales de las elecciones legislativas celebradas el 28 de junio de 2009 también tenían su causa -según el gobierno - en la oposición de los medios, particularmente, el Grupo Clarín. Comenzó, entonces, una acción destinada a lograr modificar las percepciones de la sociedad y para ello se emprendió una suerte de batalla cultural. La ley de medios iba a ser uno de los puntos centrales de la estrategia.

En el proceso de sanción de la ley se producirían nuevas disonancias y fricciones. El proyecto que había obtenido media sanción en Diputados debía pasar al Senado y Cobos había ordenado al secretario parlamentario que lo girara a cinco comisiones para generar un mayor debate, si él presidía el Senado 
pues la presidenta estaba por viajar al exterior y el Vicepresidente debía asumir provisionalmente el Ejecutivo. El oficialismo pretendía que se girara sólo a dos comisiones lo que le daría un tratamiento más rápido a la sanción de la ley. El jefe de Gabinete le solicitaba públicamente a Cobos que no interfiriera en el tema. Nuevamente se lanzaba desde las filas del kirchnerismo la idea de un "neogolpismo" vinculado con el radicalismo, Clarín y Cobos. Finalmente, la Presidente viajó, fue reemplazada por Cobos y el senador Pampuro, a cargo de la presidencia del Senado, giró el proyecto sólo a dos comisiones. Fue aprobado por 44 votos a favor y 24 en contra, sin incorporarse modificaciones.

Otro momento de grave enfrentamiento de Cristina Kirchner con Cobos fue en ocasión de la constitución del Fondo del Bicentenario, en diciembre de 2009, para hacer frente a deuda del Estado nacional y con fondos provistos por el Banco Central por un monto de 6.569 millones de dólares. La medida fue cuestionada por la oposición en base al argumento de que el gobierno no podría hacer uso de tales fondos. El Poder Ejecutivo recurrió a la emisión de un decreto de necesidad y urgencia, el 15 de diciembre, para dar vida al referido fondo. Martín Redrado, Presidente del Banco Central había manifestado desde un principio su desacuerdo con la utilización de las reservas del Banco para el pago de la deuda con el exterior. Frente al protagonismo tomado por Cobos en el Senado respecto del tema, la presidenta expresó: "es extraño ver que alguien que me acompañó en la fórmula es el candidato de oposición para el próximo turno y participa en cuanta discusión hay en contra del gobierno... que aprenda cuál es el rol del Vicepresidente según la Constitución” (Cristina Kirchner reclamó 2010).

Nuevamente Cobos se vio obligado a desempatar con su decisivo voto en el Senado, en octubre de 2010. El proyecto de la oposición para elevar la jubilación mínima al $82 \%$ del salario mínimo, vital y móvil, aprobado en diputados, fue tratado por la Cámara Alta y, luego de un largo debate, el resultado de la votación arrojó 35 votos a favor de la ley y 35 en contra. Esta vez la situación era menos dramática que en ocasión de la 125 y las posiciones estaban claras. Cobos había dado su apoyo a la ley y desde el gobierno se había anunciado que de sancionarse el Poder Ejecutivo la vetaría, más allá de sus costos políticos. Y así ocurrió. Con el voto de Cobos la ley fue sancionada, con el veto de la presidenta la ley no fue promulgada. La propia presidenta señalaba que había vetado la "ley de quiebra" del Estado votada por el Parlamento y decía en relación a Cobos: "No es importante ocupar un rol, lo importante es ejercerlo como manda la Constitución y como votó la sociedad. Tenemos un Vicepresidente okupa. Pero nadie va a pedirle la renuncia. Esto que vive la Argentina nunca se vio en ninguna parte del mundo" (La Presidenta veto 2010). CFK aludía a un supuesto rol para el Vicepresidente que, en realidad, no estaba determinado en ningún lugar de la Constitución. También es cierto que un Vicepresidente no puede asumir el papel de permanente opositor y ventilar sus discrepancias ante los medios. En ese caso dejaría la "solidaridad crítica" e ingresaría en el peligroso terreno de la polarización con el riesgo de sembrar ingobernabilidad en la cúspide del poder al convertirse en un Vicepresidente opositor.

La presidenta, con diferencias de estilo, tuvo las mismas concepciones institucionales que su marido, en relación al papel de la Vicepresidencia en el entramado social y político. La figura de Cobos y sus índices de popularidad se fueron desdibujando con el correr de los meses y el acuerdo político de la "Concertación Plural" naufragó inexorablemente. 


\section{Reflexiones adicionales}

En la Argentina - como en otros países - la Vicepresidencia es vista como una institución poco relevante, pero al mismo tiempo se percibe que puede ser crucial en algún momento si llega la hora del reemplazo del Presidente. De alguna manera, esto refleja la esencia paradojal de la Vicepresidencia y del papel del Vicepresidente: de "ser nada puede pasar a ser todo" si un accidente institucional lo ubica en la presidencia. El diseño institucional de la Vicepresidencia, en la Argentina, lo aloja como Presidente nato del Senado, pero sin funciones en el campo del área del Ejecutivo. Ello permite que los Presidentes dejen a un costado al Vice en las tareas de gobierno pues casi siempre sienten que se trata de "una sombra molesta". En la Argentina, no se han desarrollado prácticas "paraconstitucionales" que ubicaran al Vice cercano al primer mandatario en funciones de gobierno. El mayor o menor papel que adquiera la Vicepresidencia, entonces, tendrá vinculación directa con el tipo de relación que se establezca entre Presidente y Vice.

A pesar de este marco normativo restrictivo, la Vicepresidencia es vista como pieza importante para la constitución de coaliciones. Fue así que, para derrotar al menemismo, en 1997 se constituyó la Alianza. Durante la formación de la Alianza era el cargo donde se visibilizaba y expresaba la existencia misma de la coalición. Incluso la integración de los ministros de las fuerzas coaligadas tuvo un papel secundario, a punto tal que no reflejaba el peso de las fuerzas que componían la coalición. La coalición partió de bases muy precarias de organización y no llegó a tener una mínima institucionalización. Respecto de la Concertación Plural, si bien nunca tuvo las pretensiones de ser estrictamente una coalición, sino que respondió al formato de "frente" tan típico del peronismo, intentaba mostrarse como un acuerdo entre el kirchnerismo y un sector del radicalismo. También aquí era la Vicepresidencia el sitio primordial donde se reflejaba la sociedad política.

En ambos casos la relación de Presidente y Vice, en el contexto de gobierno, fue el principio del fin de los acuerdos políticos. En el caso de la Alianza, la renuncia del Vicepresidente significó la descomposición progresiva de la coalición. Aunque permanecieron funcionarios y las autoridades legislativas del bloque, la situación se fue convirtiendo en insostenible pues su líder, Carlos "Chacho" Álvarez se había enfrentado personalmente al Presidente. En el caso de Cobos, la mala relación que se fue desarrollando entre la presidenta y el Vicepresidente prácticamente diluyó la misma idea de la "Concertación Plural" y llegó al punto de tensión máxima cuando tuvo que desempatar en el Senado de la Nación un proyecto muy caro para el oficialismo. Su voto en contra del proyecto oficial lo ubicó enfrentado absolutamente contra el gobierno. En los dos casos, se produjo un desplazamiento desde una solidaridad absoluta (inicial) a una no solidaridad moderada o polarizada que devino en Vicepresidentes opositores y en franco conflicto en la cúspide del poder.

Los conflictos entre Presidente y Vice en formatos institucionales como el argentino, donde el Vice prácticamente no tiene facultades ejecutivas quedan resueltos con el aislamiento del Vice o su renuncia forzada (pudiendo ocurrir o no). La estructura del gobierno no cambia substancialmente. Pero cuando existe un esquema de coalición poco institucionalizado o no consolidado (como en el caso de la Alianza), el conflicto con el Vice puede significar su disolución, sobre todo si el Vice es jefe político del partido coaligado. Si el Vice no es el jefe o líder partidario, podría quedar doblemente aislado, del Presidente y de su propio partido y la coalición salir indemne del conflicto. Así resulta que la Vicepresidencia si bien puede ser una pieza institucional que facilita la formación de coaliciones en el sistema presidencialista, también puede precipitar su disolución, sobre todo si se asienta predominantemente en la fórmula presi- 
dencial mixta. Pero el análisis sería incompleto si pensamos que el Vice opera en soledad, como se ha visto, debe relacionárselo con el propio Presidente.

¿Cuáles fueron las actitudes y comportamientos de Presidentes y Vices en los casos en análisis? En el caso de la Alianza, De la Rúa fue un Presidente Indiferente que no incluyó al Vice en el entorno del poder ni en el grupo de tareas del Ejecutivo. Álvarez fue un Vice colaborador sólo al principio. Pasó rápidamente de un esquema de solidaridad a uno no solidario y se constituyó en un Vice opositor. No hubo vuelta atrás en la decisión asumida por el Vice. La relación entre Presidente y Vice transitó rápidamente desde la confianza a la desconfianza, llegando luego a la tensión y a la oposición. En el caso, como se señaló, no se había constituido una coalición institucionalizada y todo parecía quedar en términos del arreglo básico de la presidencia en manos de un partido y la Vicepresidencia en manos del otro. Pero el Vice era, además, jefe del partido coaligado. En este sentido, la mala relación entre Presidente y Vice fue el principio anunciado del naufragio final.

En el caso de la Concertación Plural, Cristina fue una Presidente Excluyente y no le dio a Cobos prácticamente ningún papel en su gobierno. Cobos fue pasando de una actitud de colaborador pasivo a colaborador crítico. Cuando se produjo la votación de desempate en el Senado, pasó a convertirse en un Vicepresidente opositor - para el kirchnerismo en un Vice conspirador - y Cristina Fernández trató de aislar y encapsular aún más a su Vicepresidente. En este caso no se trataba de una coalición sino de un acuerdo que sellaba la "Concertación Plural", pero ésta era absolutamente endeble y poco institucionalizada. Cobos aparecía como el líder de este espacio. Frente a la relación de desconfianza y luego tensión y oposición entre los miembros de la fórmula, el acuerdo dejó de existir.

¿Significa lo resumido que la actitud del Presidente generó las reacciones del Vice? No necesariamente. También la actitud de los Vices pudo haber llevado a los Presidentes a las actitudes finales de exclusión y hasta hostigamiento (en el caso de Cristina), aunque cabe señalar que ni De la Rúa ni Cristina Kirchner nunca fueron Presidentes Incluyentes. Y, además, no cabe perder de vista el posible comportamiento estratégico de un Vicepresidente que considera más provechoso el distanciamiento - gradual o abrupto - del Presidente. En el caso de Álvarez el distanciamiento provino cuando todavía la administración del Presidente no estaba comprometida y fue su actitud la que comenzó un desgaste en la coalición que no tendría fin. Respecto de Cobos, el perfil opositor aparece en el contexto de una crisis severa - como fue la del campo - y donde no se sabía cómo iba a concluir. Luego de esa crisis la popularidad presidencial sufrió una baja y al año siguiente perdió las elecciones de medio término.

No puede decirse, entonces, que sólo la Presidencia Indiferente o Excluyente de los mandatarios hayan generado el comportamiento de los Vices, pues estos últimos tampoco aparecían muy comprometidos activamente con sus Presidentes. El clima de tensión y de conflicto entre los componentes de las fórmulas se produjo en estadios tempranos del mandato. Cabría preguntarse si hubiera sido distinto en caso de haber existido Presidencias Incluyentes. Obviamente, se trata de un contra factual, pero nos permite pensar hipotéticos escenarios alternativos. Quizá, en el caso del gobierno de la Alianza, un Presidente Incluyente hubiera evitado la salida abrupta del Vicepresidente, en octubre de 2000, y la disolución agónica de la Alianza. Probablemente hubiera postergado la caída pues está claro que se trataba de una coalición poco institucionalizada. Y en el caso de Cobos, una improbable Presidenta Incluyente que hubiera comprometido al Vicepresidente quizá hubiera logrado su voto "positivo" en la crucial votación sobre el campo, en el Senado, 
preservando además el acuerdo de la "Concertación Plural". El voto "no positivo" de Cobos fue algo traumático para el Vicepresidente quien se mostró extremadamente incómodo y tenso en la sesión, y no pudo siquiera decir que votaba negativamente. Por otro lado, cabe recordar que Cobos había sido expulsado "de por vida" del radicalismo, en septiembre de 2007, por su presencia en la fórmula del kirchnerismo. Cobos se encontraba en un territorio paradójico: había sido expulsado del radicalismo y la fuerza con la cual se aliaba no terminaba de incorporarlo y hasta lo hostigaba. Su "voto no positivo" y su resistencia posterior contra los ataques del gobierno que integraba le volvió a abrir las puertas del radicalismo, cuando en 2009 levantó las suspensiones contra Cobos.

En síntesis, las actitudes y comportamientos de los Presidentes y sus Vices generaron un clima de tensión y conflicto que se transmitió directamente a la coalición en un caso y al acuerdo político en el otro. Cuando las coaliciones son poco institucionalizadas y reposan en la fórmula presidencial, el cuidado de la relación entre los componentes del binomio es un tema que puede ser crucial. No escapa a este análisis que la Argentina ha tenido un problema histórico en la conformación de coaliciones de gobierno, pero el atajo de recurrir a un Vicepresidente para sellar un acuerdo político no ha sido la mejor salida. La Vicepresidencia puede ser un recurso importante para sellar coaliciones, pero no suple la ingeniería institucional y el compromiso político que las hace viables.

Mario Daniel Serrafero (mserrafero@gmail.com) es Doctor en Ciencia Política y Sociología pela Universidad Complutense Instituto Universitario Ortega y Gasset y Doctor en Derecho pela Universidad de Buenos Aires. Es Profesor de la Universidad de Buenos Aires, Facultad de Ciencias Sociales e Investigador Principal del CONICET. Vinculación Institucional: Facultad de Ciencias Sociales, UBA, Buenos Aires, Argentina.

\section{Referencias}

Altman, D., 2000. The Politics of Coalition Formation and Survival in Multiparty Presidential Democracies. The Case of Uruguay, 1989-1999. Party Politics, 6(3), pp.259-283. DOI: 10.1177/1354068800006003001

Álvarez, C. \& Morales Solá, J., 2002. Sin Excusas. Buenos Aires: Sudamericana.

Neto, A.O. \& Samuels, D., 2010. Democratic Regimes and Cabinet Politics: A Global Perspective. Revista Ibero-Americana de Estudos Legislativos, 1(1), pp.12-23. DOI: 10.12660/riel.v1.n1.2010.4123

Chasquetti, D., 2006. La supervivencia de las coaliciones presidenciales de gobierno en América Latina. POSTData, 11, pp.163-192.

Cheibub, J.A.; Przerorski, A. \& Saiegh, S., 2004. Government Coalitions and Legislative Success under Presidentialism and Parliamentarism. British Journal of Political Science, 34(4), pp.565-587. DOI: 10.1017/s0007123404000195

Dávila, M., 2013. Los gabinetes de la concertación en Chile (1990 - 2010). América Latina Hoy, 64, pp.67-94.

Deheza, G.I., 1998. Gobiernos de coalición en el sistema presidencial: América del Sur. In D. Nohlen \& M.B. Fernández, eds. El presidencialismo renovado. Instituciones y cambio político en América Latina, Caracas: Nueva Sociedad.

Downs, A., 1973. Teoría económica de la democracia. Madrid: Aguilar.

Fernández Meijide, G., 2007. La Ilusión. El fracaso de la Alianza visto por dentro. Buenos Aires: Sudamericana.

Goldstein, J., 1982. The Modern American Vice Presidency. Princeton: Princeton University Press.

2008. The Rising Power of the Modern Vice Presidency. Presidential Studies Quarterly, 38(3), pp.374-389. DOI: 10.1111/j.1741-5705.2008.02650.x

Inácio, M., 2013. Escogiendo ministros y formando políticos: los partidos en gabinetes multipartidistas. América Latina Hoy, 64, pp.41-66.

Jozami, E., 2004. Final sin gloria. Un balance del Frepaso y de la Alianza. Buenos Aires: Biblos.

Laver, M. \& Budge, I., eds. 1993. Party Policy and Coalition Government in Western Europe. London: Macmillan.

Laver, M. \& Shepsle, K., 1990. Government Coalitions and Intraparty Politics. British Journal of Political Science, 20(4), p.489. DOI: $10.1017 / \mathrm{s} 0007123400005950$

Light, P.C., 1984. Vice Presidential Power. Baltimore: The Johns Hopkins University Press.

Marsteintredet, L., 2013. The Vice-Presidency in Latin America: A Safety Valve for Peaceful Presidential Succession or a Source for Instability? In Midwest Political Science Association Meeting. Chicago.

Mieres, P. \& Pampín, E., 2015. La trayectoria de los Vicepresidentes en los regímenes presidencialistas de América. Revista de Estudios Políticos, 167, pp.99-132. 
Nolte, D., 1999. Alianzas electorales y coaliciones de gobierno como símbolos del cambio político en América Latina. Revista Argentina de Ciencia Política, 3, pp.11-26.

Reniu, J. \& Albala, A., 2012. Los gobiernos de coalición y su incidencia sobre los presidencialismos latinoamericanos: el caso del Cono Sur. Estudios Políticos, 26, pp.161-214.

Riker, W.H., 1962. The Theory of Political Coalitions. New Haven: Yale University Press.

Serrafero, M.D., 1999. El poder y su sombra: los Vicepresidentes. Buenos Aires: Editorial Belgrano. 2013. Hacia una nueva Vicepresidencia. Reflexiones desde el caso norteamericano. Revista de Derecho Político, 88, pp.367 - 392.

Shribman, A., 2009. La Vicepresidencia Argentina (1982-2009). Cuadernos de Estudos Latino-Americanos, 10, pp.11-141.

Strøm, K.; Budge, I. \& Laver, M., 1994. Constraints on Government Formation in Parliamentary Democracies. American Journal of Political Science, 38, pp.303-335.

\section{Artículos de periódicos}

Cobos: "Hay que buscar no sólo votos, sino consensos". 2008. LaPolitica Online, 26 jun. Disponible en http://www.lapoliticaonline.com/nota/nota-23847/, acceso em 15.03.2018.

Cristina Kirchner reclamó que la dejen governar. 2010. La Nación, 9 ene. Disponible en https://www.lanacion.com.ar/1220142-cristina-kirchner-reclamo-que-la-dejen-gobernar, acceso em 15.03.2018.

Fernando Laborba, La escena contradictoria de una extraña pareja. 2000. La Nación, 1 oct. Disponible en https://www.lanacion.com.ar/211026-la-escena-contradictoria-de-una-extrana-pareja, acceso em 15.03.2018.

La Presidenta vetó el 82\% y calificó de "okupa" a Cobos. 2010. La Nación, 15 oct. Disponible en https://www.lanacion.com.ar/1315113-la-presidenta-veto-el-82-y-califico-de-okupa-a-cobos, acceso em 15.03.2018.

Mi sociedad política con De la Rúa fue algo imperdonable. 2002. Clarín, 3 nov. Disponible en http://edant.clarin.com/suplementos/zona/2002/11/03/z-00401.htm, acceso em 15.03.2018.

Joaquín Morales Solá, Carencias y defectos del Gobierno. 2000. La Nación, 25 jun. Disponible en https://www.lanacion.com.ar/22203-carencias-y-defectos-del-gobierno.htm, acceso em 15.03.2018.

Gustavo Ybarra, Tras una dramática sesión, el Vicepresidente Cobos desempató la votación al rechazar el proyecto oficial de retenciones. 2008. La Nación, 17 jul. Disponible en https://www.lanacion.com.ar/1030952-tras-una-dramatica-sesion-el-vicepresidente-cobos-desempato-la-votacion-al-re chazar-el-proyecto-oficial-de-retenciones, acceso em 15.03.2018.

The Vice Presidency and the Political Coalitions: the case of Argentina

ABSTRACT Introduction: This study covers the role of Vice presidencies and their role in the consolidation of political coalitions. Vice Presidency in Latin America is not a thoroughly - researched institution. Its functions and faculties vary across the regions countries, but there is one that is common to all of them: replacing the president should he or she become temporarily or definitively absent. This paper analyzes this developments in Argentina and it covers the case of Alianza government (1999-2001) and that of Cristina Kirchner and her Concertación Plural (2007-2011). In both cases the president was chosen from a different party than that of the President, one that form part of a coalition or political agreement. Methods: This study considers some factors that are normative, while others that are political. With respect to normative factors we must especially consider the faculties, attributes and competences that the Constitution assigns to the Vice President. Among the political factors its worth highlighting the method of Vice-presidential appointment, the relationship thats establish between the President and the Vice President, the role assigned to the Vice President by the President, the performance and method under that role and the weight of political influences, they both represent. Results: The results of this study show the importance of the relationship between the President and the Vice President for the maintenance of the coalitions that are not very institutionalized, and where the Vice Presidents faculties are either ambiguous or reduced. Discussion: The results of the paper bring a different perspective of the discussion regarding the functions and utility of Vice Presidents, especially when their role is to seal agreements or coalitions. This paper presents a classification of the types of Presidents and Vice Presidents and the various combinations that could result in either cooperation or conflict, and could influence the success or failure of a coalition.

KEYWORDS: Vice presidency; political coalitions; presidency; presidentialism; Latin America.

This is an Open Access article distributed under the terms of the Creative Commons Attribution Non-Commercial License which permits unrestricted non-commercial use, distribution, and reproduction in any medium provided the original work is properly cited. 


\section{Apéndice 1. Tipos de Vicepresidente y de Presidente}

Los atributos esenciales de los tipos de Vicepresidente y de Presidente son indicadores que se reflejan en el siguiente cuadro y se ponderan en una escala de 0 a 10. La asignación de los valores se hace de acuerdo a la realidad política que se intentó describir en el desarrollo de los casos, pero no deja de tener una inevitable dosis de subjetividad. Por este último motivo, la distinción esencial en los tipos de Vicepresidentes es entre Vices colaboradores u opositores y en los tipos presidenciales es entre Presidentes Incluyentes o Presidentes Indiferentes/Excluyentes (la ubicación más precisa en otros tipos depende de la lectura o interpretación que se haga de los hechos que obviamente admite cierta flexibilidad). La asignación de valores para los tipos de Vicepresidente se realiza a partir de la emergencia de conflictos significativos con el Presidente (pues al comienzo de los gobiernos los Vicepresidentes son, generalmente, colaboradores). La asignación de valores para los tipos de Presidente se realiza a partir del comienzo de la gestión presidencial (Cuadro 1A y 2A).

Se utiliza una escala de 0 a 10 para medir los comportamientos definidos en los tipos.

Vicepresidente

a) El mayor puntaje para el acuerdo total con las políticas del Presidente hasta llegar a ninguno.

b) El mayor puntaje para el cumplimiento de los pedidos del Presidente hasta llegar a ninguno.

c) El mayor puntaje para la exposición pública de las posiciones positivas del Vice y el menor para la exposición pública de sus posiciones negativas.

d) El mayor puntaje para la menor distancia ideológica del Vice con el Presidente, el menor puntaje para la mayor distancia.

e) El mayor puntaje para la relación más armónica del Vice con el Presidente, el menor puntaje para la más conflictiva.

Vice colaborador activo: 41 - 50

Vice colaborador passivo: 31 - 40

Vice colaborador crítico: 21 - 30

Vice opositor moderado: 11 - 20

Vice opositor extremo: 0 - 10

Presidente

1) El mayor puntaje para las reuniones frecuentes con el Vicepresidente para evaluar la marcha del gobierno, hasta llegar a la falta de reuniones como mínimo valor.

2) El mayor puntaje para la presencia regular del Vice en las reuniones del gabinete, hasta su ausencia.

3) El mayor puntaje para el que integra al Vicepresidente en la mesa chica de toma de decisiones o lo consulta para las decisiones importantes, el menor puntaje para el Presidente que excluye al Vice o no lo consulta para las decisiones importantes.

Presidente Incluyente: 21 - 30

Presidente Indiferente: 10 - 20

Presidente Excluyente: 0 - 9 
Cuadro 1A - Asignación de los valores a los atributos esenciales de los tipos de Vicepresidente

\begin{tabular}{lcc}
\hline Indicadores & \multicolumn{2}{c}{ Tipos de Vicepresidente } \\
\cline { 2 - 3 } & Chacho Alvarez & Julio Cobos \\
\hline Acuerdo con las políticas del Presidente & 2 & 4 \\
Cumplimiento de los pedidos del Presidente & 2 & 2 \\
Exposición pública de las posiciones del Vicepresidente & 0 & 2 \\
Sintonía ideológica con el Presidente & 2 & 4 \\
Conflictos con el Presidente & 2 & 2 \\
Total & 8 & 14 \\
\hline
\end{tabular}

Fuente: Elaboración propia.

Cuadro 2A - Asignación de los valores a los atributos esenciales de los tipos de Presidente

\section{Indicadores}

Reuniones con el Vice para evaluar la marcha del gobierno

Presencia del Vice en las reuniones de gabinete

Presencia del Vice en la mesa chica/consulta para la toma de decisiones importantes

Total

Fuente: Elaboración propia.
Tipos de Presidente

Fernando de la Rúa Cristina Fernández

3

90

1

13

1 